\title{
HIV PREVENTION AMONG DRUG AND ALCOHOL USERS: MODELS OF INTERVENTION IN KENYA
}

\author{
Clement S. Deveau \\ Academy for Educational Development (AED) \\ Capable Partners Program (CAP) \\ Nairobi, Kenya
}

\begin{abstract}
The spread of HIV among drug and alcohol users, as a high-risk group, is a significant problem in Africa, as in other parts of the world. Few programs have been implemented in Africa to deal specifically with this issue. Since November 2006, the AED Capable Partners Program in Kenya project has provided technical direction to eight Kenyan NGOs to design and implement programs to reduce the spread of HIV among this population. Programs were developed utilizing conventional outreach models modified for application in Kenya and various other communitybased interventions geared to reduce HIV among substance abusers. In addition to outreach, programs also provide components of recovery services, VCT and general HIV education in varying degrees. The effectiveness of these programs is reviewed in this paper along with the need to develop advanced technical skills of NGOs to deliver more effective services.
\end{abstract}

KEY WORDS: Alcohol, drug, community outreach, HIV and AIDS, Kenya

\section{INTRODUCTION}

The abuse of drugs and alcohol in Kenya and its relationship to the spread of HIV has been an issue of growing concern. Excessive or problem alcohol consumption has been identified in many parts of Kenya, including the rural areas where many local brews are produced. Alcohol is reported to be the most commonly abused substance, with a national abuse rate of $36.3 \%$ (Ndetei et al. 2006). A study of individuals who attended medical clinics in western Kenya revealed that $54 \%$ of the patients reported hazardous drinking behavior as measured by the Alcohol Use Disorders Identification Test (AUDIT) (Shaffer et al. 2004). Another study indicated that $66 \%$ of all alcohol drinkers were hazardous drinkers (Mackenzie \& Karusa, 2007). Like alcohol, the abuse of drugs in Kenya has increased in recent years. The abuse of heroin became common in the 1980s in larger coastal towns. Since then, heroin abuse has spread to other parts of Kenya, including smaller towns and villages, along with a growth in heroin injection (Beckerleg, Tekfer, \& Hundt, 2005).

Drug and alcohol abuse play a significant role in the spread of HIV. Substance abuse in terms of HIV risk is defined here as any recurrent consumption of alcohol or drugs that would lead to HIV risk behaviors. The

Corresponding author: Clement S. Deveau, Academy for Educational Development (AED), Capable Partners Program (CAP), ABC Place, Waiyaki Way, Westlands, P.O. Box 14500-00800, Nairobi, Kenva Tel: (254) 20-4260000 or Mobile: (254) 721169338 
link between HIV and injecting drug users has been clearly demonstrated: a study in Kenya revealed that $49.5 \%$ of injecting drug users (IDUs) tested HIV positive (Ndetei et al. 2006). Various studies also have indicated that alcohol is a significant risk factor for HIV (Assefa et al, 2005; Bryant, 2006, Weiser el al, 2006). Alcohol use has been linked to a greater risk of acquiring the HIV virus because of its disinhibiting effect (Zablotska et al. 2006). In addition to the increased risk of acquiring HIV, problem drug and alcohol users also are at greater risk of transmitting HIV to the general population. In an operations research study of clients attending VCT centers in Kenya, it was found that $60 \%$ percent of individuals who drank alcohol had multiple sexual partners (Mackenzie \& Karusa, 2007).

With the increase in drug and alcohol abuse and the link to HIV, it has become even more critical to identify both HIV risk-reduction programs among substance abusers as a high risk population and recovery treatment strategies for drug and alcohol abuse. Unfortunately, limited resources have been available to treat alcohol and drug addiction in many African countries. Furthermore, targeting substance abusers as a high risk population in HIV reduction strategies has emerged as a critical area of concern only recently. Kenya is fortunate to have some resources, although many treatment centers have limited knowledge and training in providing addiction recovery treatment services and almost no experience in integrating HIV reduction programs. This article describes various models implemented through eight NGO groups as part of the AED Capable Partners Program in Kenya to address HIV among substance abusers. Programs began operation as early as October 2006.

\section{DEVELOPING AND \\ IMPLEMENTING COMMUNITY \\ BASED HIV REDUCTION \\ PROGRAMS AMONG SUBSTANCE \\ ABUSERS IN KENYA}

The AED Capable Partners Program in Kenya has worked with NGOs based in five urban areas of Kenya specifically focused on reducing the spread of HIV among the substance abusing population. The NGOs were: Asumbi Project, Catholic Diocese of Homa Bay, Nairobi; Family Health Options Kenya, Kisumu \& Nakuru; Kisumu Urban Apostolate Programmes - Pandipieri, Kisumu; The Omari Project, Malindi; The Raphaelites, Tuangamize Ulevi Na Ukimwi (TUNU) Project, Kiambu District, Nairobi; Reachout Centre Trust, Mombasa; Support for Addictions Prevention and Treatment in Africa (SAPTA), Nairobi, Mombasa, Kisumu; Impact Research \& Development Organization (ImpactRDO), Tuungane Project, Kisumu.

These programs were designed to address the needs specific to each community. Historically, the coastal region and Nairobi have been the main centers for the distribution and use of heroin. Alcohol abuse has been the focus of programs in western Kenya, as well as generally throughout all other parts of Kenya. The basic program designs borrowed from internationally-accepted best practice models. In addition, each program incorporated various types of interventions to which it felt the community would best respond. The NGOs' current knowledge and strengths in the area of HIV and substance abuse were assessed so as to develop even more effective target-specific programs for substance abusers.

The initial challenge was to identify, through a selection process, organizations that have sufficient experience in HIV 
and substance abuse. No single NGO had significant expertise in both HIV and substance abuse. Some were primarily focused on addictions treatment rehabilitation with some HIV knowledge; others were focused on HIV with some limited knowledge of substance abuse. The approach was to help each of the NGO groups to develop strengths in the areas in which they had less expertise and to design effective programs to deal with HIV among the substance abusing population

Seven of the eight NGOs implemented community-based HIVreduction programs among substance abusers at risk of infection and transmission. The eighth NGO focused primarily on training in addiction and HIV. They developed the capacity of twenty addictions treatment centers throughout Kenya to provide more effective recovery treatment services and integrate HIV-reduction programs. This NGO's second concentration was training existing VCT counselors throughout Kenya to screen VCT clients for substance abuse using both the AUDIT and CAGE alcohol assessement tools, and then to provide those clients with brief interventions and referrals.

HIV programs designed to deal with substance abusers traditionally have been focused primarily on IDUs and to employ risk reduction strategies concentrating on the HIV risk behaviors of injecting and sexual transmission. Most of these interventions have utilized conventional outreach models. However, several different models emerged through the process described above. These include: Outreach, Community education/sensitization, HIV testing, HIV case management for the HIV positive, addictions recovery treatment, programs and services located within HIV treatment centers.

\section{MODELS/INTERVENTIONS TO REDUCE HIV AMONG SUBSTANCE ABUSERS}

\section{Outreach}

Outreach was clearly the most common method used and was implemented by all the NGOs. For the purposes of this paper, outreach is defined as activities occurring directly in the community that engaged substanceabusing clients in one-on-one or small group behavior change. However, the NGOs' approaches to outreach varied significantly, as did the success or effectiveness of each NGO's outreach work.

Most programs employed outreach workers as either full-time or part-time staff, although some programs used volunteers and some of these volunteers received stipends. Staff usually included both recovering alcohol or drug users and non-recovering individuals.

Outreach work focused primarily on HIV-risk reduction with clients, including: information and education on sexual risk behavior, appropriate use of condoms, choice of partners, sharing of injecting equipment, etc. The outreach strategy was not only informational but focused on engaging clients in order to achieve a behavior change associated with HIV risk behaviors. Workers engaged clients in repeated or follow-up sessions to assist them in creating individually specific risk-reduction plans and to help them adhere to those plans once they were developed. The majority of the work took place in the community, in drug using dens, formal and informal drinking establishments, local hang outs, and users' homes.

All outreach programs referred clients to HIV testing, primarily VCT. However, the management of and referrals for HIV testing varied significantly among the 
different organizations, as did follow-up services after the testing. In addition to VCT referrals, all outreach programs provided referrals for addictions recovery treatment services, although the level of follow-up and management of referrals again varied greatly among the NGOs. An actual diagnosis meeting the DSM-IV-TR (Diagnostic and statistical manual of mental disorders) criteria of substance abuse or dependency was not made by the outreach workers, although, recurrent use of a substance which leads to risky sexual behavior could possibly meet the criteria for DSM-IV-TR substance abuse criteria 2 or 4 , depending on other clinical history. (American Psychiatric Association, 2000). Most outreach programs also had integrated recovery treatment services available.

Outreach programs provided the most effective, measurable behavior change, a result supported by the literature (Needle, R.H. et al, 2005; WHO, 2004). One-onone outreach approaches that followed clients over time allowed for better outcomes in producing behavior change associated with HIV risk than one-time contacts with clients. Since outreach programs provided the best outcomes in terms of behavior change among substance abusers, it is helpful to compare elements that contributed to the success of certain outreach programs. For example, outreach programs that relied solely on volunteer outreach workers had the poorest outcomes in terms of work performance and client behavior change.

Table 1 compares three NGOs doing outreach work, one using volunteer outreach workers and two using paid outreach workers.

Table 1. Comparison of NGOs doing outreach work

\begin{tabular}{|c|c|c|c|}
\hline Outreach information & NGO A & NBO B & NGO C \\
\hline Type of outreach workers & $\begin{array}{l}\text { All volunteer } \\
\text { outreach workers } \\
\text { including } 2 \text { stipend } \\
\text { volunteers }\end{array}$ & $\begin{array}{l}\text { Six full- } \\
\text { time } \\
\text { outreach } \\
\text { workers }\end{array}$ & $\begin{array}{l}\text { Six full- } \\
\text { time } \\
\text { outreach } \\
\text { workers }\end{array}$ \\
\hline Total trained to do outreach & 51 & 6 & 6 \\
\hline $\begin{array}{l}\text { Actual number of outreach } \\
\text { workers doing outreach contacts }\end{array}$ & 16 & 6 & 6 \\
\hline $\begin{array}{l}\text { Total number of clients reached } \\
\text { through outreach contacts }\end{array}$ & 515 & 2286 & 4551 \\
\hline $\begin{array}{l}\text { Average number of outreach } \\
\text { clients per worker providing } \\
\text { outreach }\end{array}$ & $\begin{array}{c}32 \\
(515 / 16)\end{array}$ & $\begin{array}{c}381 \\
(2286 / 6)\end{array}$ & $\begin{array}{c}159 \\
(4551 / 6)\end{array}$ \\
\hline
\end{tabular}

The concept of community volunteers doing outreach work was not as successful. More than eight times the number of volunteers were trained and the program reached a significantly smaller number of clients as compared to the other two NGOs. In addition, 33\% $(171 / 515)$ of the volunteer contacts were made by the two stipend volunteers. Given the level of training and motivation required to provide professional outreach services to substance abusers, using volunteers as outreach workers may have its limitations.

Providing volunteer outreach workers with a stipend was of some benefit when 
tying the stipend to minimum performance targets. While all of the volunteer outreach workers attended trainings, only a small percentage actually engaged in the work. Volunteer outreach workers performed better when they were part of an experienced team of full or part-time outreach workers.

Another characteristic of the outreach programs that provided mixed results was the use of recovering drug and alcohol users as outreach workers. Recovering users require many supports to prevent relapse. Unfortunately, there was an extremely high relapse rate among recovering users who were often terminated due to poor performance and relapse issues. However, recovering addicts were valuable in identifying using sites and personally knew many of the users, making them vital in providing non-users with a bridge to the using population. A mix of both recovering users and non-users is perhaps the best composition for an outreach team.

As identified earlier, the seven NGO's provided outreach services, among other services, in each of their respective communities. Table 2 shows the number of substance abusing individuals reached through community outreach from February 2007 to May 2009.

Table 2. Number of substance abusing individuals in different facilities

\begin{tabular}{lr}
\hline Facility & N \\
\hline Asumbi Project & 1944 \\
Family Health Options Kenya & 7709 \\
Kisumu Urban Apostolate Programmes & 1063 \\
The Omari Project & 2588 \\
The Raphaelites & 990 \\
Reachout Centre Trust & 6636 \\
Impact Research \& Development & 7089 \\
TOTAL & $\mathbf{2 8 0 1 9}$ \\
\hline
\end{tabular}

These organizations provided varying levels of outreach with some NGOs placing a greater emphasis on other programs such as general Community Education/Sensitization. The table above reports only the outreach activities of each organization. Although limited outcome data is available, a significant number of substance abusers at risk of HIV were reached.

As part of measuring program outcome and effectiveness, outreach data were collected on baseline HIV risk behaviors during initial contact and during the subsequent follow-up contacts, providing an indication of the level of behavior change over time that could possibly be attributed to the outreach intervention. Obtaining reliable data was a challenge although one NGO had data that could be used for reporting purposes. Table 3 provides some information on baseline sexual risk behavior in terms of number of sexual partners and the utilization of condoms from initial contact and follow up contacts. These data were collected by The OMARI Project from February 2007 to May 2008, covering the areas of Malindi, Lamu and Kilifi. 
Table 3. Sexual risk behaviours at initial contact and follow-up

\begin{tabular}{|c|c|c|}
\hline Sexual risk behaviours & Initial Contact & $\begin{array}{c}\text { Follow up or Repeat } \\
\text { Contacts }\end{array}$ \\
\hline Average number of sexual & 1.7 & 1.2 \\
\hline $\begin{array}{l}\text { Partners for all clients in } \\
\text { last } 30 \text { days }\end{array}$ & $\mathrm{N}=4519 / 2623$ & $\mathrm{~N}=1276 / 1104$ \\
\hline Average number of sexual & 3.9 & 2.4 \\
\hline $\begin{array}{l}\text { Partners for all clients in } \\
\text { last } 6 \text { Months }\end{array}$ & $\mathrm{N}=10127 / 2623$ & $\mathrm{~N}=2622 / 1104$ \\
\hline Frequency of condom & $18.9 \%$ & $55.0 \%$ \\
\hline $\begin{array}{l}\text { usage during vaginal or } \\
\text { anal intercourse in past } \\
\text { week reported by clients }\end{array}$ & $(\mathrm{N}=2085 / 11024)$ & $(\mathrm{N}=1332 / 2423)$ \\
\hline $\begin{array}{l}\text { Percentage of individuals } \\
\text { using condoms at least } 50 \% \\
\text { of the time during vaginal } \\
\text { or anal intercourse in the } \\
\text { past week. }\end{array}$ & $\begin{array}{c}11.2 \% \\
(\mathrm{~N}=293 / 2623)\end{array}$ & $\begin{array}{c}23.4 \% \\
(\mathrm{~N}=258 / 1104)\end{array}$ \\
\hline
\end{tabular}

These data reflect behavior changes among the substance abusing clients, primarily in terms of their sexual risk. These outreached clients reported an overall decrease in the average number of sexual partners as well as an increase in the frequency and consistency of condom usage. The Kenya Demographic and Health Survey 2003 reported that 23.5\% of males in urban areas used condoms during their last sexual intercourse (Central Bureau of Statistics, Kenya [CBS], 2004). Since the OMARI Project clients were primarily males, $[89 \%$ $(2341 / 2623)]$, the $18.9 \%$ usage of condoms among male substance abusers falls below the average from the Kenyan survey, but is an expected outcome among this high risk population.

Despite insufficiencies in the data collection methods of other NGOs, those NGOs also reported anecdotally similar experiences in terms of increased condom usage and reduction of sexual partners, attributing client behavior changes to a more extended process of engaging with clients in problem solving and decision- making approaches to reduce their health risks.

\section{Community Education/Sensitization}

Some NGOs placed greater emphasis on what they called Community Education/Sensitization. This was primarily an educational approach, which typically provided information/education to groups of people. This often involved assemblies of local people gathered together by the local chief in order to present information associated with HIV and substance abuse. Organizations that engaged in these types of activities tended to have long-established experience in HIV prevention through education and sensitization. Examples of some of these activities include: presentations in schools, prisons, local civic groups or clubs, area chiefs' gatherings, sports events, etc.

As part of specifically targeting substance abusers, most NGO groups identified drug and alcohol using sites as part of their educational outreach. These included the "shooting dens" where IDUs 


\section{INTERVENTION IN KENYA}

inject. Other locations were areas where users smoke heroin or cannabis. Alcohol establishments were also targeted, including both the licit and illicit alcohol consuming areas.

Other NGO groups developed more focused educational sessions to better target substance-using groups in the drinking establishments, such as licensed bars and illicit drinking dens, and coupled with this, made immediate outreach follow up contacts after the presentation. Individuals who frequented the bar or den would listen to the presentation, which was primarily focused on HIV risk reduction strategies among the alcohol and drug users. The outreach workers or presenters would typically provide condoms and work with bar owners to maintain a supply of condoms. After completing the educational presentation, a team of outreach workers commenced the one-on-one outreach contacts with the participants.

Another NGO engaged clients during "moonlight outreaches". Outreach workers, in this case, went to discos and night clubs, meeting with clients in the establishments throughout the evening and providing them with condoms, educational pamphlets, and referral coupons to come to their drop in center for follow up services. On various occasions, they also provided mobile VCT clinics, pitching a tent in close proximity to the night club or disco where the outreach workers brought or referred clients for VCT testing. As part of this service, they also had an addictions counselor available to assess clients for further addictions treatment services and provide brief initial treatment interventions. The VCT testing and addictions screening typically occurred earlier in the evening, and both counselors assessed the client's ability to participate in services based on the amount of alcohol consumed and their ability to engage in either program.

These various education/sensitization strategies have limitations in being able to produce effective behavioral change among substance abusers. Since the first documented case of HIV in Kenya in 1984, many efforts have been made to disseminate information to educate the public about modes of transmission and prevention measures. As a result, most people have a basic knowledge and understanding of HIV transmission along with some knowledge of the role of drugs and alcohol in promoting risky behavior. Activities of education/sensitization among drug and alcohol users provide some benefit in reinforcing health education messages and risk reduction strategies. However, evaluating behavior change as a result of these activities can be difficult.

Today, strategies that will positively affect HIV/AIDS need to go beyond education messages to promoting and supporting behavior change. Educational strategies that specifically target the substance abusing population and include an outreach intervention with follow-up contacts are likely to have a greater impact on behavior change than general educational messages. These educational outreaches draw upon the strengths of the outreach model and can include other interventions such as HIV testing, in order to more effectively produce behavior change. The epidemic of HIV transmission is less an issue of knowledge and more about translating that knowledge into sustained behavior change.

The concept of behavior change communication and its importance in reducing the spread of HIV was highlighted through the example of Uganda. Planning and implementing behavior change communication among 
the general population and target groups was a primary factor in facilitating the decline of the HIV prevalence. The decrease in sexual partners, as a result of behavior change, was considered the most important determinant in the reduction of HIV and AIDS in the country. Additionally, behavior change cannot simply involve information and education, but must focus on fundamental behavior change approaches, which include communication methods and motivation strategies to produce changes in behavior (USAID, 2002). Sexual behavior is the preeminent area of risk in the spread of HIV. Sexual behavior change needs to be the major focus in preventing the spread of HIV. The extent of behavior change will determine the future path of the epidemic (Oster, 2007).

Substance abusers require more targeted strategies to produce behavior changes so targeting behavior change strategies among substance abusers is essential to reducing the spread of HIV among this high risk population. According to a WHO study, denial and neglect of risk were key patterns in the relationship between alcohol and sexual behavior. Denial and neglect of sexual risk were observed as a means of coping with life by the alcohol user (WHO Report, 2005).

Denial is considered part of the disease of alcoholism and drug abuse. Such denial plays a role to help users maintain and support their addiction, which effectively makes behavior change among the substance abusing population much more challenging. As a result, general educational messages are not likely to produce lasting change in risk behavior of this population.

\section{HIV Testing}

All NGOs incorporated HIV testing as an integral part of their services to clients. HIV testing services included: outreach referrals of substance abusers to existing VCTs for HIV testing; conducting mobile VCTs for HIV testing in the community; and developing specialized, on-site VCTs that could better target and test the substanceabusing population.

The demand for mobile VCT testing increased throughout the course of the program interventions. This is primarily because many substance users chose, for multiple reasons, not to go to VCT centers. The mobile VCT brought the service directly to the clients. This typically occurred after outreach workers had already identified clients for testing. A mobile VCT was scheduled on a particular day, and outreach workers sought out the users in the area to provide them easy access to VCT testing.

In the cases where the NGOs specialized in substance abuse, some chose to supplement HIV testing services by developing specialized VCT centers located directly in their drop-in centers. They employed and trained VCT counselors who specialized in testing substance abusers. This addition to their existing program greatly facilitated the referral process between outreach and VCT.

There were variations in how referrals were made and how involved an outreach worker or staff person was in facilitating the HIV (VCT) referral. The substance abuser's level of attendance or participation in VCT was clearly affected by how much he/she was engaged by the outreach worker or other staff in the referral process.

In terms of VCT testing and reporting, two NGOs (OMARI and Reachout) gathered reliable VCT referral and testing information. These data were collected from February 2008 till June 2009. 
HIV PREVENTION AMONG DRUG AND ALCOHOL USERS: MODELS OF

INTERVENTION IN KENYA

Table 4. Utilization of VCT services

\begin{tabular}{lc}
\hline VCT services & $\mathrm{N}$ \\
\hline Number of referrals for VCT testing & 9385 \\
Number VCT tests performed & 4895 \\
Number accompanied to VCT site by outreach worker & 4607 \\
Percent of referrals VCT tested that were accompanied by an & $94.1 \%$ \\
outreach worker & $(4607 / 4895)$ \\
Percent of referrals VCT tested who attended VCT on their own. & $3.1 \%(288 / 9385)$ \\
\hline
\end{tabular}

From Table 4, of all the VCT tests performed $94.1 \%(4607 / 4895)$ occurred when an outreach worker accompanied the client. Even though the outreach workers provided clients with written VCT referrals, very few actually went on their own to be tested. Only 3\% (288/9385) of those tested came on their own as a result of the referral from the outreach worker. It is possible that the number of persons tested who came on their own could be larger if the client refused to disclose to the VCT counselor that they had been referred by an outreach worker or if he/she did not provide the VCT counselor with the referral card provided by the outreach worker. Nonetheless these data are significant in that they indicate that substance abusers do not readily engage in services on their own without the support of the outreach worker.

Existing VCT centers can also be an effective entry point for screening clients who have drug and alcohol problems. One of the NGOs worked specifically with existing VCTs to provide them with the knowledge and skills to screen clients for substance abuse and provide brief intervention, as well as referrals for addiction treatment services. The inclusion of this brief intervention strategy provided clients with useful information they would otherwise not have received.

HIV testing has been a valuable tool in helping substance abusers identify their status. All programs utilized HIV testing, and VCT is the most common method because of its large scale availability and accessibility throughout Kenya. One of the challenges of VCT is incorporating more referrals to other health care providers. The orientation of VCT counselors strongly emphasizes a high degree of confidentially and subsequently, many VCT counselors are not comfortable engaging other nonmedical providers. Training of VCT testing sites has helped to facilitate more referrals to the outreach teams in order to help HIV-positive substance abusers comply with HIV treatment. Likewise, referral to outreach programs of the HIVnegative substance abusers provides these individuals with additional supports and resources to maintain their HIV negative status. In addition, as identified in the VCT data above, it is important to engage substance abuse clients in the VCT testing process. These clients tend to respond to the support offered by the outreach workers in accompanying them to VCT, but when they are simply referred to VCT by the outreach worker, their participation in VCT testing is extremely poor.

\section{HIV Case Management for the HIV Positive}

Preventing the further spread of HIV among clients who test positive is of vital importance to curb the AIDS pandemic. HIV positive substance abusers present 
unique challenges since they have a greater tendency to use substances to cope with life stressors, such as their HIV positive status. As a result of excessive alcohol use, users can often engage in risky sexual behavior (Weiser et al. 2006).

Case management for HIV positive substance abusers is one way to increase users' participation in HIV treatment and also help improve their engagement or participation in addiction recovery programs. Early intervention is critical for once the substance abuser is identified as HIV positive, the more time elapses after HIV testing, the less likely the patient will be to initiate HIV care services. Coordination by the case manager with the HIV testing sites is critical to facilitate immediate HIV care services. This is typically best done when the VCT counselor, the patient, and the case manager meet directly after testing to facilitate the care process. The case manager then tracks these clients to schedule and follow up HIV treatment services.

Outreach workers typically function as case managers, acting in this dual role since they know best how to access their clients in the community. Other NGO staff may take on this role as well, provided they know how to access these clients in the community. One NGO included, as part their regular program, the stipulation that their VCT counselors also manage the HIV care of the drug and alcohol using clients.

Case management for the HIV positive substance abusing client ensures that this vulnerable population, many of whom would not participate in HIV care services, receives necessary HIV treatment. VCT counselors and outreach workers doing follow ups on the HIV positive clients, report that approximately $80-90 \%$ of these clients will not initiate
HIV care services without the support or accompaniment by the outreach worker or VCT counselor to the facility. Even with intensive case management services, one NGO (Reachout) reported that they were able to actively engage $52 \%(133 / 255)$ of all their known HIV positive clients in HIV treatment and care through the outreach case management program. If the VCT testing center is able to link the client with the case management service immediately, the likelihood of follow through with services is more promising. Ideally, the case manger will bring the client to the HIV treatment center the following day. With the client's consent, the case manger typically will go to the home of the client and accompany the client to his/her appointment. This usually will continue until all the major diagnostic work has been completed and a course of HIV treatment is in place. Without this level of intensive case management, substance abusing clients typically only initiate HIV treatment services when their condition has deteriorated and they are in need of acute medical care.

\section{Addictions Recovery Treatment}

Addictions recovery treatment services were typically part of the continuum of care within most of the NGOs' programs. Clients were identified by outreach workers, VCT counselors, and community members and then referred for recovery treatment. Most of these services were on an outpatient basis with referrals to residential programs as needed. These services were established relatively recently, with many of the staff being novices in addictions counseling. They conducted clinical intakes/ assessments, individual and group counseling, and intensive outpatient treatment. They also referred clients to medical practitioners for detoxification 
services and facilitated referrals to residential rehabilitation services.

While addictions recovery treatment was offered as part of most programs, the quality varied greatly. Few people have been trained to provide addictions counseling. Many of the NGO staff do not have the knowledge and skill level necessary to administer good quality treatment programs. As a result, client engagement is limited and participation is poor. Clients have traditionally sought out these services expecting to be cured from their dependency so they tend to become quickly discouraged and drop out of services when provided only with information about recovery. However, clients are now becoming more aware of their need for on-going counseling services and are beginning to participate more actively in the services available to them.

Sustaining recovery is also a problem for clients who participate in both residential and non-residential services. Most clients cannot afford residential treatment and therefore they participate in whatever no-cost non-residential treatment is available. Relapse rates are high especially among opiate users.

Addiction recovery, on its own does not provide a good HIV risk reduction model because of its poor outcome to achieve and sustain recovery. However, addictions recovery services, as part of an integrated HIV program for substance abusers, can play a valuable role in reducing the spread of HIV. Substance abusers who have achieved abstinence are at lower risk of acquiring HIV as compared to active users. IDUs who do not participate in substance abuse treatment are up to six times more likely to become infected with HIV as compared to IDUs who participate in substance abuse treatment (CDC, 2002). Relapse seems to provide some benefit in that it helps the user understand how powerful his/her addiction is, and is often the basis for a stronger commitment to recovery. In this case, relapse in substance abusers gives the service provider an opportunity to emphasize the necessity of a full commitment of the abuser to a recovery program rather than the abuser seeking unrealistic curative fixes from treatment providers.

Increased training and improvement in professional practices should render more favorable recovery outcomes for clients. Amidst the challenges, training programs that have been underway for more than a year are witnessing improvements in the skill level of addictions counselors. There also seems to be an increasing recognition among users that active participation in recovery treatment services is essential in order to achieve sobriety. In addition, clients are more receptive to ongoing recovery programs, such as 12-step self-help, and therefore can achieve more sustained recovery.

Although addictions recovery treatment services cannot necessarily be seen as a highly effective HIV intervention from a community health perspective, it is still an essential component of an overall HIV reduction strategy.

\section{Commercial Sex Workers and Alcohol}

Licensed bars are often a popular venue for professional female commercial sex workers and illicit drinking dens are a common site for the low-end sex workers. These illicit drinking dens will include local women who frequent these establishments to exchange sex for money as their primary occupation and women who will present themselves when they become more desperate for money to feed their children, for example. The latter group engages in the activity on periodic 
occasions, only when they are in need of money. This sex work tends to be unsophisticated, usually inexpensive, and often with limited protection.

Most of these women are involved in alcohol consumption, especially the commercial female sex workers. In a study of bar-based female sex workers, consumption of alcohol was associated with increased sexual risk taking. This also was demonstrated in the study which showed a higher sexually transmitted infection (STI) incidence among this population when consuming alcohol (Yadav et al, 2005). One NGO (The Raphaelites) has established a specialized four-week intensive outpatient alcohol/drug treatment program for these women and employs them as part-time outreach workers in their program, after completing treatment. They reported that the early successes of this program were due to ongoing participation in an alcohol/drug recovery program. They also stated that sustained alcohol recovery is the key factor in discontinuing sex work. Their observation is that relapse into alcohol or drugs leads to reengagement in the sex work.

\section{Programs and Services Located Within HIV Treatment Centers}

A pilot project by one of the NGOs was initiated to work with HIV positive substance abusers in an HIV treatment center. The project was developed to offer services to HIV positive substance abusers receiving HIV treatment at the center. These centers are often faced with many challenges in providing services to HIV positive substance abusers. For instance, many substance abusers conceal or deny their alcohol or drug abuse or they do not adhere to their ARVs thus compromising their treatment plan. The HIV care centers also lack the resources and skills to deal with these challenges and termination of ARV treatment often becomes the reality for these patients.

This NGO (The Raphaelites) provided specialized onsite services as part of an integrated service plan. Adherence and substance abuse classes were provided for clients on ARVs. Addictions recovery services were also provided on site and scheduled during the time when clients returned for ARVs. Case management was provided and coordinated with the health care professionals and HIV community health workers to follow the care of substance abusing clients. Outreach risk reduction services were provided as part of the organization's outreach program but identified for clients receiving HIV care at the treatment center.

This pilot project provided the most integrated approach to managing HIV care and treatment for the HIV positive substance abuser than the other models we have reviewed. Substance abusers received support services and became more engaged in their treatment plan, with the goal of this plan being to help sustain them on ARVs rather than terminating their treatment. Strategies such as recovery abstinence and, to the extent possible, managing the consumption of drugs and alcohol were also utilized.

Specific outcomes for this program are not yet available, although the medical staff reports that the case management of HIV positive substance abusers is beneficial in supporting ARV compliance for this population. This innovative approach provides hope for improving HIV treatment outcomes for substance abusing patients, while reducing the risk of possible transmission to others.

\section{CONCLUSION}

In reviewing each of the modalities utilized by the various NGOs, it becomes 
clear that a multi-faceted approach is necessary. Although outreach demonstrated the most favorable results, it was clear from a review of the various programs that outreach programs should not be implemented in isolation. Other support services such as VCT testing, case management, and education/ sensitization campaigns are necessary for such programs to succeed.

The most effective outreach programs included teams made up of recovering and non recovering outreach workers. Recovering outreach workers, to be effective, needed to achieve a period of sobriety for at least one year and be engaged in some type of recovery program. Utilizing community volunteers for outreach can have some benefit, but it often made it difficult to obtain reliable outcomes. The most reliable data came from the more experienced NGOs who implemented outreach programs with fulltime staff. Full and part-time outreach workers were able to demonstrate, through information and data collection, a tangible reduction had occurred in sexual risk behavior from first contact to repeated contacts in terms of number of sexual partners as well as an increase in condom usage. Observations and concrete data from the NGOs also reinforce the accepted notion that one-on-one types of outreach strategies were more effective in altering behavior in substance abusers than education/sensitization campaigns to community groups, even though the latter reported higher numbers of contacts in recorded data.

The more successful programs also demonstrated the necessity of engaging substance abusers over time in order to achieve the desirable behavior change. Follow up contacts helped to establish a rapport with the client necessary to sustaining them through the individual's ongoing change process.
It is also clear from the VCT referral data collected by NGOs that the substance abusing population does not respond well to traditional referrals for services. They require an added level of case management intervention in order to guide and support them through the process of HIV testing and subsequent HIV treatment services for the HIV positive client. Without such programs, participation by this high-risk population likely will be extremely limited.

Substance abusers require skilled interventions in order to produce sustained behavior change in HIV risk behaviors. Without sufficient training and skills, workers in outreach programs could exert only a limited impact for their efforts. To provide effective outreach services, behavior change strategies and individualized action plans need to be developed and followed through with clients. Without rigorous programming geared to the specific needs of such a population, few changes can be achieved among this hard-to-reach group.

One of the key findings was the importance of the outreach workers themselves, particularly those whose skills were further refined by training and experience. A well-managed outreach program that can provide the necessary support services is able to reach a significant number of substance abusers, and have a meaningful impact on HIV risk behaviors among this high-risk population.

\section{REFERENCES}

American Psychiatric Association. (2000). Diagnostic and statistical manual of mental disorders (4th ed., text revision). Washington, DC: Author.

Assefa, S., Damen, M.H., Alemayehu, W. (2005). The association between substance abuse and HIV infection among people visiting HIV counseling 
and testing centers in Addis Ababa, Ethiopia. The Ethiopian Journal of Health Development, 12(2), 116-125.

Beckerleg, S., Telfer, M., \& Hundt, G. L. (2005). The rise of injecting drug use in east Africa: a case study from Kenya. Harm Reduction Journal, 2(12). doi:10.1186/1477-7517-2-12

Bryant K. J. (2006). Expanding research on the role of alcohol consumption and related risks in the prevention and treatment of HIV/AIDS. Substance Use and Misuse, 41: 1465-1507.

Central Bureau of Statistics, Kenya [CB]), Ministry of Health [MOH], \& ORC Macro. (2004). Kenya Demographic and Health Survey 2003. Calverton, Maryland, USA: CBS, MOH and ORC Macro.

CDC (2002, February). Substance Abuse Treatment for Injection Drug Users: A Strategy with many benefits: fact sheet.

Centers for Disease Control and Prevention. Department of Health and Human Services.

Kwena, Z.A. (2004). Politics, Etiquette, and the Fight Against HIV/AIDS in Kenya: Negotiating for a Common Front. Africa Development, (Vol. XXIX, No. 4, pp. 113-131).

Mackenzie, C., Kiragu, K. (2007, January). Should voluntary counseling and testing counselors address alcohol use with clients? Findings from an operations research study in Kenya, Horizons Research Update. Nairobi: Population Council.

Ndetei, D.M., Ongecha, F.A., Malow, R.M., Onyancha,J., Mutiso, V., Kokonya, D.D., et al. (2006). Next Priorities for Intervention in Kenya: Results from a Cohort Study of Drug Use, HIV and HCV Patterns in Five Urban Areas. International Psychology Reporter, 10(1): 16-19.

Needle, R.H., Burrows, D., Friedman, S.R., Dorabjee, J., Touzé, G., Badrieva, L., et al. (2005). Effectiveness of Community-
Based Outreach in Preventing HIV/AIDS Among Injecting Drug Users. International Journal of Drug Policy, 16(1) 45-57.

Oster, E. (2007). HIV and sexual behavior change: why not Africa? University of Chicago and NBER. Cambridge, MA: National Bureau of Economic Research.

Shaffer, D.N., Njeri, R., Justice, A.C., Odero, W.W., Tierney, W.M. (2004). Alcohol abuse among patients with and without HIV infection attending public clinics in Western Kenya. East African Medical Journal, 81(11): 594-599.

USAID (2002, September). What Happened in Uganda? Project Lessons Learned Case Study. United States Agency for International Development; Edited by J.A. Hogle.

WHO (2004). Evidence for Action: Effectiveness of Community-Based Outreach in Preventing HIV/AIDS Among Injecting Drug Users. World Health Organization, Geneva.

WHO Report (2005). Alcohol Use and Sexual Risk Behaviour: A Cross-Cultural Study in Eight Countries. Geneva: World Health Organization.

Weiser, S.D., Leiter, K., Heisler, M., McFarland, W., Percy-de Korte, F., et al. (2006). A population-based study on alcohol and high-risk sexual behaviors in Botswana. PLoS Medicine, 3(10): e392: 1940-1948. doi: 10.1371/journal. pmed.0030392

Yadav, G., Saskin, R., Ngugi, E., Kimani, K., Keli, F., Fonck, K., et al. (2005). Associations of Sexual Risk Taking Among Kenyan Female Sex Workers After Enrollment in an HIV-1 Prevention Trial. Journal of Acquired Immune Deficiency Syndrome, 38(3): 329-334.

Zablotskaa, I.B., Graya, R.H., Serwaddab, D., Nalugodab, F., Kigozib, G., Sewankambob, N., et al. (2006). Alcohol use before sex and HIV acquisition: a longitudinal study in Rakai Uganda, AIDS, 20(8): 1191-1196. 